\title{
A SOCIALIZAÇÃO NA EDUCAÇÃO INFANTIL
}

\author{
Cristiane Moraes Pimentel ${ }^{1}$ \\ Cleuza da Silva Freire ${ }^{2}$ \\ Dagmar Modesto Batista Barros ${ }^{3}$ \\ Fernanda Viana Pinheiro 4 \\ Irineide Santos Costa ${ }^{5}$ \\ Mickyciele da Silva Caldas Almeida ${ }^{6}$ \\ Verônica Delgado do Nascimento Barbosa ${ }^{7}$
}

RESUMO: Este artigo buscou apresentar princípios e conceitos básicos da educação infantil, associados às questões relacionadas à socialização e à prática educativa de crianças, atividades e recursos educacionais. A educação infantil ensina e prepara as crianças para as fases posteriores da educação. O objetivo deste artigo é discutir a importância das interações que ocorrem no espaço escolar como meio de construção da aprendizagem, pois na educação infantil as crianças têm maior probabilidade de aprender mais e a socialização é fundamental para isso.

Palavras-chave: Criança. Educação Infantil. Aprendizagem. Socialização.

ABSTRACT: This article sought to present basic principles and concepts of early childhood education, associated with issues related to socialization and educational practice of children, activities and educational resources. Early childhood education teaches and prepares children for the later stages of education. The aim of this article is to discuss the importance of interactions that take place in the school space as a means of building learning, as in early childhood education children are more likely to learn more and socialization is essential for this.

Keywords: Child. Child education. Learning. Socialization

\footnotetext{
I Graduada em Pedagogia pela Universidade Federal de Mato Grosso, Especialista pelas Faculdades Integradas de Várzea Grande - FIAVEC.

${ }^{2}$ Graduada em Pedagogia - Educação Infantil pela Universidade Federal de Mato Grosso, Especialista em Docência na Educação Infantil pela Universidade Federal de Mato Grosso - UFMT.

3 Graduada em Pedagogia pela Universidade de Cuiabá - UNIC, Especialista em Educação Especial Atendimento Educacional Especializado pela Faculdade de Educação de Tangará da Serra - UNISERRA.

${ }^{4}$ Graduada em Pedagogia pelas Faculdades Integradas de Várzea Grande - FIAVEC, Especialista em Educação Infantil pelas Faculdades Integradas de Várzea Grande - FIAVEC.

5 Graduada em Pedagogia pela Faculdade UNIVEST de Educação, Especialista em Educação Infantil e Letramento pela Faculdade UNIVEST de Educação.

${ }^{6}$ Graduada em Pedagogia pela Universidade Pitágoras - UNOPAR, Especialista em Educação Infantil: prática pedagógica pela Faculdade - FAVENI.

7 Graduada em Pedagogia pelo Centro Universitário Cândido Rondon - UNIRONDON, Especialização em Infantil pelas Faculdades Integradas de Várzea Grande - FIAVEC.
} 


\section{INTRODUÇÃO}

A educação infantil é uma fase onde a criança se desenvolve consideravelmente. Estudos tem comprovado a importância da socialização para o desenvolvimento da criança desta faixa etária. Assim, cabe a escola e aos professores ficarem atentos a este tema de grande importância para a educação.

A educação infantil pode ser vista como algo construtivo que fornece contribuição para o desenvolvimento sócio-intelectual da criança. Entretanto, podese perceber que durante a fase em que a criança está inserida na educação infantil é muito importante sua convivência com outras pessoas além da própria família. Desta forma, a Educação infantil é de grande importância para o desenvolvimento sociológico do indivíduo visto que além de ter interação, ele aprende a estar também convivendo com outras pessoas e isto vai contribuir para que se tenha um bom convívio posteriormente.

O ensino que é produtivo tem que estar contribuindo para que a criança amplie seu desenvolvimento e desta forma a inserção da mesma no universo escolar pode contribuir bastante para isto. A criança vai ficar preparada para lidar com situações adversas que possam aparecer no seu cotidiano dentro e fora do ambiente escolar. É assim, dever da escola deixar o aluno preparado para estas adversidades.

É na educação infantil que a criança está propensa a desenvolver-se socialmente e também a aprender. Isto irá ocorrer por meio da interação com outros adultos (professores e funcionários da instituição) e com outras crianças. Nesta fase ela tem o início de sua percepção como parte da sociedade passando a desenvolver-se de maneira mais profunda no processo de socialização.

As relações de interação que ocorrem no ambiente escola são um importante meio para se construir as aprendizagens. Crianças que estão inseridos em uma mesma faixa etária não vão possuir níveis de conhecimento iguais. Cada criança terá seu próprio nível de saberes. Assim quando existe a introdução de vivências onde a criança possa estar trocando conhecimentos com outras tem-se a construção de aprendizagens visto que a socialização é fundamental para isto. Desta maneira verifica-se a importância do tema para um maior conhecimento da pesquisadora e também de outros professores.

Quando a criança se socializa ela passa a formular novas hipóteses, construir conhecimentos coletivos por meio do diálogo e discussão de convicções. Aprendem também 
a escutar e a trabalhar em grupo passando desta maneira a sempre estarem construindo novos conceitos.

O professor ao oportunizar o trabalho em grupo, as crianças se organizam alcançando os objetivos propostos pelo educador. De modo simplificado mas com eficiência elas vão se socializando. Dessa forma percebe-se a importância do professor estar melhor organizando estes momentos de socialização da criança para que ela possa cada vez mais desenvolver novas aprendizagens em um contexto inserido na relação e interação com outros alunos. Por meio do processo de socialização ainda é possível que se potencialize situações de troca e tomada de consciência onde se tem um favorecimento da construção do conhecimento.

Entretanto existem muitos educadores que ainda mantêm a postura tradicional de transmissão de conhecimentos. Este artigo objetiva ressaltar a importância de uma nova postura inovadora na educação onde haja a mediação de conhecimentos através da interação entre professor/aluno e aluno/aluno. É por meio desta forma de interação que o aluno terá a oportunidade de construir seus próprios conhecimentos, ou seja, um processo educacional com base em troca de conhecimentos.

\section{DESENVOLVIMENTO}

\section{I Educação Infantil}

Quando vai-se refletir sobre a Educação Infantil é necessário levar em consideração a criança como um sujeito que possui desejos, ativo e cognoscente, com uma história de vida. Um indivíduo singular em sua maneira de estar no mundo e de adaptar-se, ao mesmo tempo que necessita instrumentalizar-se para modificar e reconstruir sua própria realidade.

O período da Educação Infantil é profundamente marcante, fundamental e muito curto para a criança. Apenas compreendê-lo não é suficiente. É necessário dar uma contribuição ampla para sua realização.

No período da Educação Infantil não existe a possibilidade de ensinar tudo o que a criança precisa aprender, entretanto, é possível ensinar muitas coisas a ela. Neste período tem-se a possibilidade da criança formar muitos hábitos e habilidades. Assim, este período pode ser um tempo de prazer por meio do lúdico e de aprendizagens voltadas para uma melhor vivência dos dias da infância e posteriormente os dias que vão se seguir. 
No campo da psicologia, Vygotsky, na década de 20 e 30, atestava que a criança é introduzida na cultura por parceiros mais experientes. "Wallon destacava o valor da afetividade na diferenciação que cada criança aprende a fazer entre si mesma e os outros" .(PAIVA et. alli., 2007, p. 65).

Freinet "defendia que as atividades manuais e intelectuais permitem a formação de uma disciplina pessoal e a criação do trabalho-jogo, que associa atividades e prazer e é por ele encarado como eixo central de uma escola popular" (PAIVA et. alli., 2007, p. 66). Sua pedagogia era baseada em uma série de técnicas e atividades.

$\mathrm{Na}$ atualidade a criança "deixa de ser vista como um adulto em miniatura e passa a ser observada como um ser que tem suas próprias necessidades” (BOGUS et. alli., 2007, p. $512)$.

Atualmente, pode presenciar, no cenário nacional, por intermédio de ações políticas, os frutos dessa mobilização em favor da Educação Infantil. A educação destinada à criança pequena (o a 6 anos) "passa a ser reconhecida como direito da criança e dever do Estado na Constituição Federal de 1988, o Estatuto da Criança e Adolescente, de 1990, sustenta, também, o direito dela a esse atendimento" (BOGUS, 2007, p. 512). Reafirmando o caráter educativo, a atual Lei de Diretrizes Bases da Educação Nacional integra a educação infantil à Educação Básica, juntamente com o Ensino Fundamental e Médio. "A educação infantil passa a ser considerado um nível de ensino, primeira etapa da Educação Básica, a qual deve se efetivar mediante atendimento em creches (o a 3 anos) e pré-escola ( 4 a 6 anos) de forma gratuita não" (Ibidem, p.499) obrigatória e independente da classe social, gênero, etnia e raça.

A educação infantil deve promover aprendizagens e crescimento às crianças de diversas classes sociais. "É preciso que a educação nesta fase tenha professores bem preparados para que ela tenha um bom êxito" (Ibidem, p. 98).

A atual etapa reconhece o direito de toda criança a infância. A inteligência infantil, sua linguagem e suas formas de representação passam a ser objeto de metodologias de ensino preocupadas com o saber. Pesquisas desenvolvidas em vários países e em diversos campos de conhecimento destacam o grande valor das primeiras experiências na primeira infância. Tivemos, nas últimas décadas, acesso a pesquisas que demonstram, em curto prazo, "a importância de experiências precoces e de qualidade para o desenvolvimento cognitivo, 
emocional e social da criança e, em longo prazo, para seu sucesso" (PAIVA et. al., 2007, p. 65) na escola e na vida.

\subsection{A Socialização}

A interação entre as crianças no ambiente escolar é muito importante visto que é por meio dela que tem-se a formação de discussão, opinião, discordâncias contribuindo para as aprendizagens de maneira significativa. "Freire ressalta que os sujeitos aprendem em comunhão mediatizados pelo meio, Rossato acrescenta que a educação é um processo social, e que os homens se educam conjuntamente" (PULGATTI, 2012, p. 2).

É verificável a importância de desenvolver atividades coletivas na escola que vão contribuir para a socialização, entretanto ainda fica visível que muitas vezes na escola ainda ocorre a valorização do uso de atividades individuais como uma maneira de estimular a competitividade dos saberes. Entretanto, fica claro que atividades de grupo ampliam os conhecimentos por meio da interação e da mediação.

De acordo com Neves (2006) a criança por meio da ajuda de outra com as mesmas competências e experiências podem adquirir a capacidade de adquirir uma atividade que em muitos casos não conseguiria somente com a ajuda do professor.

Segundo Rossato (2006) a educação pode ser caracterizada como um processo dialógico e com isto, verifica-se que um ambiente que busque a concretização do conhecimento deve estar fundamentado no diálogo. Assim o trabalho de maneira coletiva e cooperativa é muito importante, pois segundo Pulgatti (2012), é através desta forma de trabalho tem-se a possibilidade de construção de novas possibilidades. Já de acordo com Freire (1967) o diálogo tem uma função de constituição de consciência do indivíduo visto que a partir dele as crianças passam a tomar consciência de sua realidade.

O conhecimento deve ser percebido como resultado da relação entre os sujeitos entre si e com o mundo que os cerca. É somente pelo conhecimento que as pessoas têm a oportunidade de mudarem a si mesmas e ao mundo na qual estão inseridas. Assim, "A atividade

de ensino-aprendizagem é determinada pela interação social dos sujeitos envolvidos neste processo" (ROSSATO, 2006, p. I8). 
As crianças já possuem uma potencialidade para aprender. Entretanto, quando o aluno participa de maneira responsável pelo seu processo de aprendizagem ela se torna mais fácil de acontecer. Assim, segundo Pulgatti (2012), é importante que o aluno construa seu próprio caminho até o conhecimento. Em Freire (1996, p. 28) ele afirma que "ensinar não é transferir conhecimento, mas criar as possibilidades para sua produção ou sua construção".

Por meio da socialização, a criança tem um momento de troca onde ele se relaciona de maneira diferente com o saber. Por meio de sua interação com outras crianças, existe a construção de laços de afeto e respeito onde são evidenciadas as características individuais que compõe a identidade de cada um.

O processo de socialização contribui para o desenvolvimento da identidade e da autonomia. Por meio das interações tem-se a oportunidade de se ampliar os laços afetivos que as crianças vão estar estabelecendo umas com as outras e com os adultos próximos. Isto vai contribuir para que se tenha o reconhecimento do outro e a valorização das diferencias e o respeito das mesmas. "Ao interagir com o outro se verifica a constituição de um confronto de concepções iniciais do educando com aquelas apresentadas pelos seus pares, tornando este processo fundamental para que a criança se aproprie de novos significados, apropriação esta que só se fará pela socialização" (PULGATTI, 2012, p. 4).

A socialização é um processo contínuo de aprendizagem. Ela tem por objetivo a integração do ser humano a sociedade. É por meio dela que o indivíduo tem a oportunidade de se tornar atuante socialmente. A escola é um importante local onde esta socialização vai está ocorrendo. Em seu ambiente existem diferentes formas de interação social que contribuem para o desenvolvimento da criança.

Assim, pode-se verificar a importância do professor está trabalhando por meio da socialização da criança usando diversas atividades dirigidas ou não para que haja uma maior interação entre as mesmas. É dever da escola e principalmente do professor promover uma educação baseada na socialização de seus educandos.

\subsection{As atividades lúdicas e a socialização}

Os jogos são uma boa maneira de melhorar continuamente a Educação Infantil. São uma forma de trabalhar que não é cansativa e contribui para o desenvolvimento infantil de uma forma bastante dinâmica. Na cabeça da criança o momento do jogo e das brincadeiras 
é associado a hora de descansar e se divertir. Assim o professor possui uma ótima alternativa de ensinar por meio destes recursos que agrada tanto o público infantil.

Por meio do lúdico o aluno passa a ter uma maior facilidade em estar aprendendo e compreendendo a realidade. Ele pode ser considerado como um processo que contribui de maneira significativa para a socialização infantil visto que com seu uso a criança vai percebendo como se dão as relações humanas. Também passa a explorar de maneira mais dinâmica o espaço físico, estabelecendo cadeias de significados e ampliando a percepção do real.

O jogo - ou brincadeira - facilita a apreensão da realidade e é muito mais um processo do que um produto. Por meio dele a criança percebe como se dão as relações humanas, explora e desenvolve noções sobe o mundo físico, estabelecendo novas cadeias de significados, e amplia sua percepção do real (AROEIRA et. al, 1996, p. 19).

A infância precisa ser um espaço rico em estímulos para que se tenha o desenvolvimento da criança. Entretanto, muitas vezes as escolas que atendem este públicoalvo tornam-se cheias e saturadas, não conseguindo um número suficiente de funcionários para atender de maneira correta as crianças. Assim, muitas vezes os estímulos acabam sendo reduzidos. A educação atual deve mudar este contexto. Ela deve privilegiar a formação do educando de forma integral preparando-o para as fases posteriores.

O Referencial Curricular Nacional para a Educação Infantil afirma: $O$ desenvolvimento da identidade e da autonomia estão intimamente relacionados como os processos de socialização. Nas interações sociais se dá a ampliação dos laços afetivos que as crianças podem estabelecer com as outras crianças e com os adultos, contribuindo para que o reconhecimento do outro e a constatação das diferenças entre as pessoas sejam valorizadas e aproveitadas para o enriquecimento de si próprias. (MEC, RCNEI, I998c. v. II)

No contexto educacional da atualidade a sociedade trás consigo novas exigências que vão reivindicar práticas educacionais que tenham como ponto chave a formação do educando de maneira integral.

Assim os professores devem reconhecer que a prática pedagógicas voltada para a utilização de jogos e brincadeiras é inovadora e contribui de maneira significativa para a socialização infantil. Assim o jogo passa a obter uma função de direcionador do desenvolvimento emocional, intelectual e social da criança. De acordo com os pressupostos de Brougère (1994), os jogos e brincadeiras são compostos de regras que levam a criança a compreender melhor os posteriores processos de sua vida. Por meio deles o professor passa 
a ter uma melhor perspectiva de compreensão em relação as fases de desenvolvimento infantil.

A cultura lúdica possui grande importância para a socialização da criança. De acordo com Brougère, esta cultura se constitui "de brincadeiras conhecidas e disponíveis, tradicionais ou universais e geracionais próprias de uma geração específica” (1994, p. 50). Ela também implica em ambientes que tenham em sua composição objetos e principalmente brinquedos que possibilitem a interação da criança com eles mesmos, com outras crianças e com adultos.

Pode-se constatar também que não se tem um conceito definido a respeito do jogo. Este está relacionado como o próprio ato de jogar e pelas regras que estão inseridas no contexto deste jogo. Os brinquedos possuem uma série de significados onde a criança pode estar interpretando eles de diversas maneiras, sempre criando significados novos.

Através das brincadeiras a criança tem a oportunidade de vencer seus próprios limites. Este tipo de atividade abrange uma forte relação com o desenvolvimento humano. Por meio do lúdico a criança tem a possibilidade de descobrir a si mesma passando a compreender as melhores maneiras de conviver e socializar com os outros, lidando com situações de colaboração e competição, onde vai aprendendo a moldar suas atitudes.

\footnotetext{
Diante do que foi exposto, pode-se afirmar que o jogo, a brincadeira e a diversão fazem parte de uma importante dimensão da aula a ser desenvolvida pelos educadores, à dimensão do momento lúdico. Movimento este tão atrativo que faz com que a criança busque e viva diferentes atividades que possamvir a ser fundamentais não só no processo do desenvolvimento de sua personalidade e de seu caráter, como também ao longo da construção de seu organismo cognitivo e afetivo. Assim, um aspecto da Educação que pode promover o sucesso escolar é o

resgate do jogo, proporcionando um ambiente de amor, nas relações entre criança, conhecimento, meio, aprendizagem (BROUGÉRE, 1994, p. 13).
}

A Educação Infantil deve promover aprendizagens e crescimento as crianças de diversas classes sociais. É importante que a educação nesta fase tenha professores bem preparados para que ela tenha um bom êxito.

As crianças são capazes de aprender independente de sua cor, classe, idade. O professor deve estar atento para procurar recuperar as dificuldades apresentadas na instituição escolar. Por meio do estudo foi possível perceber que o professor deve estar buscando estratégias para intervir e contribuir para o crescimento do educando. Sendo 
assim, devemos desde agora na formação, estar buscando sempre estratégias de aprendizagens e buscar estar sempre nos renovando.

A educação infantil pode ser considerada como um espaço de vivências, interações e socialização. "Comprova-se que na educação infantil a criança está mais propensa a aprender e também a se desenvolver socialmente" (BEZERRA, OLIVEIRA, SOUZA, 20II, p. I). É um tempo importante para a educação e a construção de conhecimentos para a criança. É necessário que para isto, o professor utilize de uma diversidade de metodologias visto que uma criança não é igual a outra, assim, cada uma pensa e age de uma maneira. Isto ocorre devido a grande variedade de realidades nas quais cada indivíduo está inserido. Assim o papel do professor é de fundamental importância para estar adequando estas variações. É ele o elo que liga a criança da realidade ao imaginário.

É papel do educador planejar o espaço onde as crianças estarão inseridas no contexto escolar buscando permitir uma maior autonomia às crianças e uma maior interação com as outras crianças, com o professor e com as atividades que estarão sendo trabalhadas neste contexto.

Assim, uma área da Educação que pode promover uma melhora escolar é o uso do jogo, dando a oportunidade de se criarem ambiente extrovertido por meio da qual a aprendizagem passa a ocorrer de forma mais dinâmica. Como recurso pedagógico, a atividade lúdica favorece o desenvolvimento físico, motor, emocional, cognitivo e social do educando além de permitir a expressão das experiências adquiridas no seu contexto familiar e social.

Trabalhar com o lúdico implica em abordar o prazer fundamental no processo de organização/estruturação da subjetividade humana. Por isso mesmo, não se trata de um aspecto de menor importância a ser trabalhado nas escolas. As atividades lúdicas ou o lúdico como um fundamento dos processos formativos, implícito no desenvolvimento cognitivo e nos modos e mecanismos da aprendizagem, entre outros, supõem competências específicas e, até então, pouco aprofundadas no âmbito da educação formal. Está cada vez mais evidente que é possível produzir, aprender e trabalhar com prazer (MACHADO, 2010, p. 25).

O lúdico como atividade pedagógica favorece a aprendizagem e o desenvolvimento estudantil. É necessário dizer que, segundo Kishimoto (2009) a integração do brincar, cuidar 
e educar, apesar de defendida por estudos ainda se encontra afastada do cotidiano da maioria das instituições de ensino, no Brasil.

Nesse aspecto, ressalta-se que é fundamental para as instituições de Ensino Fundamental também valorizarem as atividades lúdicas, acreditando que, por meio dessa linguagem, muitos problemas apresentados pelos alunos na hora de aprender poderiam ser resolvidos.

Através da participação dos alunos em atividades lúdicas estimula-se a interação e a integração com os alunos, o que contribui para a ocorrência de uma aprendizagem de qualidade. "Muitos educadores defendem o desenvolvimento das atividades lúdicas, na formação da criança e jovens, pois elas são facilitadoras do acesso ao conhecimento" (NEVES, 2006, p. 5).

A atividade lúdica é uma atividade que deve permear o cotidiano das instituições de ensino; ver o lúdico como uma atividade que engloba aspectos importantes ao aprendizado (ROSSATO, 2006). É importante frisar que as atividades lúdicas bem trabalhadas levam o educando a pensar, agir, sentir, aprender e desenvolver-se, enquadrando nesse tipo de atividade os jogos, brincadeiras, dança, leitura, passeios, dramatizações, et.

Ao estimular os educandos com atividades lúdicas que são realizadas no seu meio, o professor tem em suas mãos o universo cultural delas, facilitando, assim, a sua atuação no sentido de enriquecer as experiências lúdicas desses alunos, além de permitir que conheça melhor a realidade de cada um.

Desse modo, permite aos educandos uma forma de assimilar a cultura de maneira criativa, social e partilhada. Para Kishimoto (2009) esse enriquecimento das atividades lúdicas pode ser feito através da organização do espaço, de atividades com elementos culturais, jogos com regras mais rígidas, etc.

É fundamental ao professor quando trabalhar com atividades lúdicas se colocar como participante, acompanhando todo o processo das atividades e mediando os conhecimentos, com o propósito de desenvolver os alunos, de forma rica e prazerosa. É importante lembrar que, para as experiências lúdicas se tornem ricas aprendizagens, é necessário que as atividades lúdicas sejam adequadas ao estágio de desenvolvimento dos educandos.

Através da participação dos alunos em atividades lúdicas estimula-se a interação e a integração com os alunos, o que contribui para a ocorrência de uma aprendizagem de 
qualidade. Para Bogus (2007, p.5) "Muitos educadores defendem o desenvolvimento das atividades lúdicas, na formação de crianças e jovens, pois elas são facilitadoras do acesso ao conhecimento" (AROEIRA, 1996, p. 3) que: "a preocupação do educador não é, pois, só ensinar o conteúdo, mas ensinar a viver, e a ludicidade é uma alternativa para mostrar que existem várias formas de ensinar, aprender e construir a aprendizagem.

Para ampliar a socialização uma boa atividade, é por meio do lúdico, este possibilita que o professor passe a ter um maior conhecimento e interação com a criança pois nestes momentos ela se sente mais a vontade e libera o que tem dentro de si passando desta forma a transmitir ao educador sua bagagem e suas necessidades, podendo assim, o professor fazer um diagnóstico para detectar o que pode ser trabalhado no desenvolvimento daquela criança. As atividades lúdicas são importantes para a aprendizagem.

Para Brougère: Ao utilizar a expressão "atividades lúdicas”, refiro-me a atividades que abordem ações como: jogar, representar, desenhar, pintar, dramatizar, experimentar e outras; levando o aluno a familiarizar-se com diferentes linguagens e formas de expressão: imagens, músicas, mapas, obras de arte, textos, histórias em quadrinhos, desenhos e outros materiais (I994, p. I).

Através das atividades lúdicas é possível reconhecer os educandos como sujeitos sociais plenos e ativos, capazes de fazer a própria história de si mesmo e do mundo que os cerca. O papel do professor é dar orientação e estímulo e acompanhar e coordenar o aluno na exploração dos jogos.

Para Vygotsky, o desenvolvimento humano constrói desde o nascimento onde a criança interage com outras pessoas, principalmente aquelas envolvidas afetivamente com sua educação e cuidados.

Muitas tarefas não podem ser feitas pela criança sozinha. Entretanto, ela acaba tendo a capacidade de realizálas se alguém lhe der instruções para fazê-la. Para compreender o desenvolvimento da criança, é necessário levar em consideração o nível de desenvolvimento real e também o nível de desenvolvimento potencial infantil, ou seja, a capacidade de desenvolver tarefas com a ajuda de adultos ou de companheiros mais capazes. "O processo de socialização infantil desenvolve-se nas interações da criança com o seu meio, e dentre os agentes colaboradores neste processo podemos citar a família, os meios de comunicação, pessoas do seu convívio, professores e a escola" (MACHADO, 2010, p.i9). 
O papel do professor no processo de socialização é o mediador, devendo facilitar a aproximação entre as crianças. É preciso escolher práticas de comunicação próprios de cada faixa etária das crianças, sempre analisando as singularidades do grupo, buscando conhecer o nível de autonomia de cada uma sempre buscar colocar desafios que vão impor a elas a necessidade de manter relação para resolver os problemas por meio da parceria de seus pares. Um professor que vai trabalhar com o infantil, precisa conhecer a criança. É preciso ser um observador para conhecer o outro. É preciso conhecer os processos de desenvolvimento da criança para saber em qual fase ela se encontra e poder contribuir para que ela se desenvolva cada vez mais.

O desenvolvimento acontece através da relação com o outro, sendo este adulto ou outras crianças. Assim o professor deve estar buscando e incentivando esta socialização e interação para a criança.

A escola precisa estimular a criança a brincar durante a educação infantil buscando ampliar o desenvolvimento da linguagem, estimulando a participação e a socialização. Para que a criança tenha uma socialização saudável é necessário espaço e segurança, com pessoas capacitadas para dar suporte buscando o desenvolvimento de suas potencialidades. $\mathrm{Na}$ educação infantil, a interação da criança com outras possibilita o desenvolvimento de uma auto imagem positiva de si mesma sentindo-se confiante e segura investindo nas trocas de afetividade.

Os adultos devem promover encontros sociais, para que as crianças tenham a oportunidade de descobrir o prazer da convivência. Logo que a criança é concebida tem-se o início do processo de socialização. Mesmo no útero a criança ouve e tem contato com as pessoas que estão ao seu redor, estabelecendo assim, as primeiras relações com o mundo.

Entretanto, é apenas através das relações dia a dia que ela vai ter a oportunidade de descobrir o prazer das relações. Desde que a criança nasce a interlocução das pessoas com o bebê vão favorecer o seu desenvolvimento social.

Através das brincadeiras o bebê busca sua atenção por meio de palavras, toques e movimentos estimulam o processo de socialização levando ao seu desenvolvimento. É por meio dos exercícios constantes que a criança vai descobrindo como pode se comunicar e com quem tem interesse em estabelecer este tipo de comunicação. Através destas observações é possível verificar que a socialização que ocorre na Educação Infantil se dá em diversos 
momentos, entre eles as atividades lúdicas, envolvendo jogos, brincadeiras e recreação livre. Estas situações favorecem o desenvolvimento de aprendizagens nas crianças, inclusive aprendizados sociais, sobre regras de conduta sociais e morais.

Neste contexto é importante ressaltar o papel do professor, que deve ser o de fornecer uma estrutura dentro da qual as crianças possam interagir, contestando, resolvendo problemas, testando ideias e encontrando estratégias de aprendizagem. (MACHADO, 2010, p.45) A partir do momento em que a criança vai crescendo, ela vai descobrindo outras maneiras de relacionar-se com o mundo que a cerca desta forma, é importante que passem a vivenciar diferentes situações.

Assim pode-se oferecer diversificados tipos de brinquedos, não se esquecendo que é de suma importância a interação da criança com adultos e com outras crianças visto que entre iguais as trocas são autênticas. Os adultos vão fazer as intervenções necessárias no processo de socialização entre as crianças. É eles que vão dar segurança para a superação dos desafios que possam vir a aparecer.

A escola surge com o papel de promover o encontro das crianças visando desenvolver habilidades cognitivas, motoras, relações afetivas, busca oferecer espaços e oportunidades de interação para que as crianças tenham a oportunidade de descobrir o que é socializar-se.

\section{${ }_{3}$ CONCLUSÃO}

Este artigo teve como objetivo refletir a importância da socialização na educação infantil e quais os fatores que contribuem para sua ocorrência, assim como práticas pedagógicas voltadas para a socialização e o papel da escola e do professor nesse processo.

É importante estudar como o brincar se relaciona com a socialização, bem como a contribuição da primeira para a segunda atividade ocorre em sua totalidade.

A educação infantil é uma forma de abordagem de socialização que oferece uma série de benefícios de desenvolvimento para as crianças. Eles permitem diferentes tipos de aprendizagem para os alunos, bem como permitem que crianças da mesma idade apresentem diferentes níveis de aprendizagem. A socialização auxilia na ampliação das relações e no desenvolvimento infantil, bem como na construção do aprendizado. Durante a socialização, a criança começa a construir conhecimento coletivo, formular hipóteses e aprender a 
implementar ideias de grupo. Por meio da interação, os atores estabelecem uma troca que permite a construção de novos conceitos.

Para tornar a aula mais interessante, é preciso motivar os alunos a aprender. A sala de aula torna-se mais agradável para professores e alunos, facilitando o processo ensinoaprendizagem por meio do lúdico e da socialização.

É através do processo de socialização que a criança passa a compreender o mundo por meio das experiências vividas. $\mathrm{Na}$ família ocorrem as primeiras interações sociais, mas a escola é onde as crianças começam a conhecer seus colegas e os professores começam a estabelecer novas interações com o grupo. Os relacionamentos no mundo de hoje estão cheios de regras não ditas e significados complicados.

A socialização permite que as crianças se desenvolvam plenamente e adquiram novas habilidades. A criança tem a oportunidade de se relacionar e trocar sentimentos, passando a se relacionar totalmente com os outros.

Quando ocorre interação, as crianças frequentemente discordam, resultando em ideias conflitantes. De acordo com este artigo, pode-se verificar que isso é benéfico para o desenvolvimento cognitivo dos indivíduos envolvidos, uma vez que esses conflitos levam à formulação de hipóteses complexas, que levam à criação de conjuntos na aprendizagem.

\section{REFERÊNCIAS}

AROEIRA, Maria Luísa C. et. al. Didática de pré-escola: vida criança: brincar e aprender. São Paulo: FTD, 1996.

BEZERRA, Ana Paula Gonçalves.; OLIVEIRA, Márcia Cardoso de.; SOUZA, Silvana Aparecida Silva. Socialização na Educação Infantil. 201 .

BÓGUS, Cláudia Maria; NOGUEIRA-MARTINS, Maria Cezira Fantini; MORAES, Denise Ely Belloto de e TADDEI, José Augusto de Aguiar Carrazedo. Cuidados oferecidos pelas creches: percepções de mães e educadoras. Rev. Nutr. [online]. 2007, vol.20, n.5, pp.499514. Disponível em https://repositorio.unifesp.br. Acesso em I4/II/202I.

BRASIL. Ministério da Educação e do Desporto, Secretaria de Educação Fundamental. Referencial Curricular Nacional para a Educação Infantil. Brasília: MEC/SEF, 1998.

BROUGÈRE, G.B. Brinque e Cultura. São Paulo: Cortez, I994. 
FREIRE, Paulo. Educação como prática de liberdade. Rio de Janeiro: Paz e Terra, 1967.

Pedagogia da Autonomia: Saberes necessários a prática educativa. São Paulo: Paz e Terra, 1996 .

KISHIMOTO, TizukoMorchida. (org.) O jogo, o Brinquedo, a Brincadeira e a Educação. 8ª ed. São Paulo: Cortez, 2009.

MACHADO, Quélen Daiani Zanoelo. Socializar brincando: uma experiências prática na Educação Infantil. Porto Alegre: UFRGS, 2010. Disponível em http://www.lume.ufrgs.br. Acesso em I4/II/202I.

NEVES, Rita de Araújo. Vygotsky e as teorias de aprendizagem. UNI revista, 2006 PAIVA, Núbia Silva Guimarães et. al. Educação Infantil. Paracatu: FINOM, 2007. I82p

PULGATTI, Larissa Manuella Santos. A importância da socialização no processo de ensino aprendizagem. Santa Maria: UFSM, 2012.

ROSSATO, Ricardo. Século XXI saberes em construção. Passo Fundo: Ed. Universidade de Passo Fundo, 2006. 